\title{
CUIDAR DE IDOSOS: UM ASSUNTO DE MULHER?
}

\author{
Camila Rafael Ferreira \\ Universidade Federal de São Carlos (UFSCar) \\ Letícia Isaac \\ Universidade Federal de São Carlos (UFSCar) \\ Vanessa Santiago Ximenes \\ Universidade Federal de São Carlos (UFSCar)
}

\begin{abstract}
Resumo
O gênero é considerado por muitos pesquisadores um fator que influencia a escolha do cuidador de idosos. Essa revisão narrativa visa refletir sobre a ação da cultura como agente determinante na escolha da mulher como responsável pelo cuidar. Este artigo preconiza a redefinição do critério de escolha dos cuidadores, de forma a estabelecer o papel de cuidar para o familiar mais apto a realizá-lo, não sendo o gênero o seu determinante. Espera-se reforçar a necessidade de desenvolvimento de políticas sociais direcionadas à mulher, considerando a sobrecarga que acomete o cuidador. Discute-se o valor social atribuído à atividade de cuidado e a importância de torná-la mais favorável a quem a exerce. Conclui-se que debater sobre a influência da cultura nessa atividade predominantemente feminina é uma tarefa ardilosa, porém necessária quando se visa melhorias para os envolvidos no contexto do cuidar.
\end{abstract}

Palavras-chave: Cultura; Gênero; Mulheres; Cuidadores, Idosos.

\section{CARING FOR THE ELDERLY: A WOMEN'S ISSUE?}

\begin{abstract}
Gender is considered for many researchers a factor that influences the elderly's caregiver choice. This narrative review aims to reflect about the culture as determinant agent of woman's choice as responsible for caring. This article recommends a review of the criteria for choosing caregivers, in order to establish the role of caring to the family member that is more capable to accomplish it, not being genre its major determinant. We reinforce the need for developing social policies focusing on women, considering the burden that affects caregivers. It is discussed the social value attributed to caring activity and the importance of making it more favorable to caregivers. It is concluded that debating on the influence of culture on this predominantly female activity is a complex task, but necessary when it is aimed improvements for those involved in the context of caring.
\end{abstract}

Keywords: Culture; Gender; Women; Caregivers, Aged

\section{CUIDAR DE ANCIANO: ¿UN ASUNTO DE MUJER?}

\section{Resumen}

El género es considerado por muchos investigadores un factor que influye en la elección del cuidador de ancianos. Esta revisión narrativa pretende reflexionar sobre la acción de la cultura como agente determinante en la elección de la mujer como responsable por el cuidado. Este artículo preconiza la redefinición de los criterios de elección del cuidador de forma a establecer el papel del cuidador para el familiar más apto a realizarlo, no siendo el género determinante. Se espera reforzar la necesidad del desarrollo de políticas sociales dirigidas a la mujer, considerando la sobrecarga que acomete al cuidador. Se discute el valor social atribuido a la actividad de cuidado y a la importancia de tornarla más favorable a quien la ejerce. Debatir sobre la influencia de la cultura de esta actividad predominantemente femenina es una tarea difícil, más necesaria cuando se pretende mejoras para los participantes en el contexto de cuidar. Palabras claves: Cultura; Mujeres; Género; Cuidadores; Adultos Mayores. 


\section{INTRODUÇÃO}

Em decorrência da elevação na expectativa de vida no Brasil e no mundo, e consequente aumento da população idosa, é possível observar a ampliação no número de casos de demências e fragilidades, visto que a idade é o principal fator de risco para o surgimento desses quadros (Burlá, Py, \& Scharfstein, 2010; Brasil \& Andrade, 2013; Leite, Menezes, Lyra, \& Araújo, 2014). Neste cenário, a necessidade por cuidadores que assistirão idosos em suas demandas torna-se evidente (Neri, 2014). Além disso, estudos que busquem compreender a relação entre fatores cronológicos, biológicos, psicológicos, sociais e culturais (Schneider \& Irigaray, 2008) presentes no processo de envelhecimento fazem-se imprescindíveis para um entendimento acerca da complexidade de se tornar um cuidador de idosos (Barham, Pinto, Andrade, Lorenzini, \& Ferreira, 2015).

De acordo com a Lei no 10.741, de $1^{\circ}$ de outubro de 2003 (Presidência da República, Casa Civil, Subchefia para Assuntos Jurídicos, 2003), é obrigação da família, da comunidade, da sociedade e do poder público cuidar do bem-estar e dos direitos da pessoa idosa. Porém, o que se percebe no Brasil é esse cuidado majoritariamente sendo delegado às famílias (Bauab \& Emmel, 2014; Debert \& Oliveira, 2015; Pinto, Barham, \& Albuquerque, 2013). Quando a atividade de cuidar é assumida por familiares, ela é geralmente realizada por um único membro da família, que tem que dividir essa nova função com outras obrigações que já lhe eram designadas (Perracini \& Neri, 2012). Portanto, ao se pensar em envelhecimento de uma forma ampliada, é preciso, também, pensar acerca das pessoas que irão cuidar desse idoso.

Segundo o Ministério do Trabalho (2016), na Classificação Brasileira de Ocupações, o cuidador é a pessoa que "cuida de idosos a partir de objetivos estabelecidos por instituições especializadas ou responsáveis diretos, zelando pelo bem-estar, saúde, alimentação, higiene pessoal, educação, cultura, recreação e lazer da pessoa assistida". Ao que se percebe, ao cuidador são atribuídas diversas funções. Por isso, delimitar quem é o cuidador de idosos pode ser uma tarefa complexa, visto que o grau de dependência dos idosos, o nível de envolvimento e as funções delegadas para cada cuidador podem variar. Essa dificuldade em delimitar quem é um cuidador faz com que pessoas que muitas vezes não apresentam papéis tão similares sejam inseridas em uma mesma categoria. Uma alternativa para refinar essa definição é especificar os cuidadores quanto ao nível de envolvimento (primário, secundário e terciário) ou pelo tipo de cuidado prestado (cuidador formal ou informal) (Neri, 2014).

Pesquisadores apontam que a designação de quem prestará cuidados ao idoso decorre de quatro fatores: parentesco, gênero, proximidade física (viver junto) e proximidade afetiva (Karsch, 2003; Perracini \& Neri, 2012). Desses quatro elementos, tem-se o gênero como o principal determinante na escolha do cuidador. A evidência que nos permite fazer essa afirmação é que, independente 
de qual recorte é feito para delimitar o tipo de cuidador que estamos nos referindo, percebe-se que o grupo que compõe a categoria será formado majoritariamente de mulheres. Assim, pode-se dizer que há uma predeterminação de quem será o cuidador, uma vez que existe uma expectativa social para que seja a mulher a assumir esse papel, visto que cuidar da família e realizar tarefas domésticas são funções tidas como "naturalmente" femininas (Silva \& Santana, 2014).

Nessa direção, Berg e Woods (2009) afirmam ser uma convenção social que a mulher seja aquela que presta cuidados. Desse modo, a cultura em que se está inserido parece estabelecer funções quase que estanques aos homens e às mulheres e ainda que estas estejam cada vez mais inseridas no mercado de trabalho, quando há necessidade de cuidados por parte de qualquer um dos membros familiares, existe uma pressão social e familiar para que elas os prestem (Camargo, 2010).

O fracionamento de lugares sociais entre gêneros caminha pela história, estando presente no modo de vida nômade, passando pelas sociedades agricultoras, e chega à Idade Moderna, selada pela Revolução Industrial e pelo crescimento exponencial da participação da mulher no setor produtivo observado até os dias atuais (Carvalho, Cavalcanti, Almeida, \& Bastos, 2008). Tais transformações certificam que desde tempos remotos há distinções entre tarefas realizadas por cada gênero, sendo tal demarcação de funções uma construção cultural ensinada ao longo de gerações. Não seria diferente quando se reflete acerca da atividade de cuidar de idosos.

Assim, o papel de assistência atribuído à mulher parece ser fruto de uma construção histórica e social, em que desde criança as meninas são ensinadas a realizar tarefas de cuidado, criando sobre elas a expectativa de que exerçam o papel de cuidadora quando necessário ao longo de suas vidas. Logo, pode-se designar a cultura como um elemento norteador para a escolha de quem assistirá ao idoso em seu processo de envelhecimento.

Após breve contextualização, tem-se que o objetivo deste artigo consiste em realizar uma reflexão crítica acerca da influência da cultura e dos papéis de gênero na escolha do cuidador de idosos. A fim de explanar acerca de tais aspectos, foram selecionados textos, sem delimitação de período de publicação, que fundamentam a área de estudo relativa a cuidadores de idosos e obras da abordagem behaviorista radical que trazem reflexões sobre a cultura.

Assim, a escolha dos textos foi baseada em uma reconstrução lógica e crítica dos argumentos que fundamentam o tema proposto, isto é, a cultura enquanto determinante para a escolha de cuidadores de idosos. Por fim, com o embasamento teórico sólido, foram problematizados tópicos acerca do objetivo proposto, de forma a discutir as consequências relativas ao tema bem como 
sugestões de estratégias viáveis e benéficas a serem implantadas na sociedade a curto e longo prazo, como forma de minimizar os impactos da atividade de cuidar de idosos. Dessa maneira, entendendo que a ocupação "cuidador de idosos" é uma função relativamente recente no cenário brasileiro justifica-se a presente discussão sobre o tema dada a escassez de estudos que problematizem o gênero enquanto fator principal na decisão acerca de quem será o cuidador e principalmente, dada a necessidade de adaptações frente às mudanças sociodemográficas do Brasil. Para tanto, serão abordados os seguintes aspectos: a) a cultura e seus efeitos na vida em sociedade; b) a mulher como cuidadora; c) impactos na saúde do cuidador(a) e d) questionamentos sobre a tarefa de cuidar de idosos.

\section{A cultura e seus efeitos na vida em sociedade}

Ao considerar o termo cultura, várias imagens, palavras e símbolos podem vir à tona. Contudo, assim como aponta Moreira (2013), pode-se facilmente defini-la, porém apenas se não for pedido para se fazer tal feito. Não é prioridade neste texto discutir todas as variantes pertencentes ao conceito de cultura, todavia, não se ater minimamente a sua definição poderá tornar a leitura descontextualizada. Cultura pode ser conceituada a partir de múltiplas acepções e especificidades, bem como, pode-se valer da relação com outros termos para ser então definida (Moreira, 2013).

De acordo com Skinner (2003), cultura é entendida como o ambiente social. Sendo o ser humano um ser social, isto é, imbricado em relações interpessoais, é capaz de emitir um tipo específico de comportamento, denominado de comportamento social. Tal comportamento é definido como "o comportamento de duas ou mais pessoas, uma em relação à outra ou (dessas pessoas) em conjunto, em relação a um ambiente comum" (Skinner, 2003, p. 297) e surge porque um organismo é importante para outro enquanto parte de seu ambiente, isto é, o comportamento de um indivíduo passa a ser ambiente ora assumindo a função de estímulo antecedente, ora de consequente - ao qual outra pessoa responde. Assim, quando parte de um ambiente de uma pessoa são outras pessoas, tem-se um comportamento social e o ambiente presente neste contexto é o ambiente social, ou a cultura.

Nessa direção, Moreira (2013) afirma:

A cultura se refere às contingências de reforçamento social que produzem e mantém o comportamento das pessoas de um determinado grupo social, cuja existência vai além do período de vida dos membros do grupo. Normalmente, essas contingências são formuladas por meio de regras e leis que constituem os costumes, tradições, etc., habituais de um povo: o modo como se vestem, comem, como criam os filhos, como se governam, e assim por diante. Ou seja, é um conjunto particular de condições no qual um grande número de pessoas se desenvolve e vive. (p. 16) 
O que Moreira nomeia como "costumes, tradições" e "o modo como se vestem, comem, como criam os filhos, como se governam" são comportamentos que são reforçados e mantidos em determinada cultura. Tais comportamentos são denominados de práticas culturais (Skinner, 1983), consideradas como "replicadores da cultura" (Baum, 2006), por serem modeladas, reforçadas diferencialmente pela sociedade e transmitidas aos membros do grupo e de uma geração a outra, enquanto uma aprendizagem social. Esta aprendizagem estaria alocada no terceiro nível de seleção por consequências (Skinner, 1981), que descreve as formas pelas quais os membros do grupo aprendem por intermédio de seus pares, produzindo e acumulando conhecimento ao longo de várias gerações (Martone \& Todorov, 2007).

É importante mencionar que, além do terceiro nível de seleção (i.e., aprendizagem social), Skinner (1981) enuncia também outros dois níveis de determinação do comportamento: o nível filogenético e o ontogenético ou operante. No nível filogenético, fala-se de variações genéticas que podem determinar a sobrevivência e reprodução da espécie, podendo então serem mantidas e transmitidas de uma geração a outra. Já na ontogênese, tem-se a história de aprendizagem do indivíduo, que se dá por meio do processo de condicionamento operante. A seleção de comportamentos operantes deve-se ao reforçamento diferencial de respostas (Moreira, 2013).

Todos os três níveis de determinação do comportamento têm como princípio causal o processo de seleção pelas consequências $e$, apesar de existirem eventos sociais e não sociais, a aprendizagem de tais eventos acontece por meio dos mesmos processos comportamentais, que são a imitação, a exposição direta às contingências de reforço e o papel do comportamento verbal, mais especificamente das regras, no controle do comportamento (Moreira, 2013).

As regras figuram como elemento de grande relevância na evolução e na manutenção dos padrões culturais, pois o comportamento governado por regras é aprendido mais rapidamente do que a exposição direta às contingências, sendo basilar na aprendizagem de comportamentos envolvidos nas práticas culturais (Malott, 1999). Nessa direção, Carvalho et al. (2008) pontuam que é por meio do comportamento verbal (regras, instruções) que as crianças entram em contato com seus parceiros sociais que the descreverão o "conhecimento do mundo externo e dos papéis sociais nele prescritos" (p. 438).

Dessa maneira, a transmissão de práticas culturais é então possível a partir da participação de cada membro do grupo. Segundo Skinner (2003), "à medida que cada indivíduo vem se conformar com os padrões de conduta também vem a apoiar o padrão ao aplicar uma classificação semelhante ao comportamento de outros" (p. 455). Isto é, o grupo, na figura de cada membro deste, exerce controle por meio de seu poder de reforçar (comportamentos classificados como "moral", "certo", "bom") e punir (comportamentos ditos como 
"imoral", "errado", "ruim"), ou seja, duas ou mais pessoas podem se organizar de forma a controlar o comportamento de outra(s) (Skinner, 2003).

O poder de controle pelo grupo, quando mais organizado, passa a ser exercido por agências controladoras, que manipulam conjuntos particulares de variáveis. Dentre elas, têm-se o governo, religião, psicoterapia, economia e educação. Tais agências atuam como o grupo, reforçando e punindo comportamentos, porém com maior sucesso que este. Logo, agências de controle, que são indivíduos se comportando de modo organizado e consistente, contribuem para a manutenção e propagação de determinadas práticas culturais (Skinner, 2003).

Dessa forma, a partir dos conceitos de cultura, de práticas culturais e de poder de controle pelo grupo/agências controladoras, pode-se fazer uma extrapolação na direção da assertiva de que os comportamentos que se atribui a homens e mulheres - ou o que se rotula como "papéis de gênero", são construções culturais selecionadas que descrevem comportamentos predominantemente femininos e masculinos.

\section{A mulher como cuidadora}

Sinnot e Shifren (2001) afirmam que gênero é o que a cultura faz com as evidências do sexo biológico. Isto é, a partir da constatação da anatomia reprodutiva (órgãos "reprodutores"), a cultura passa a imperar de forma a moldar o recém-nascido ao formato que lhe cabe, assumindo como pano de fundo os estereótipos de gênero pouco permissivos à variabilidade.

Conforme afirmam Cabral e Díaz (1998), "por ter genitais femininos ou masculinos, eles (meninos e meninas) são ensinados pelo pai, mãe, família, escola, mídia, sociedade em geral, diferentes modos de pensar, de sentir, de atuar" (p. 1). Quanto à criação dessas estereotipias de gênero, Scott (1995) pontua:

O termo "gênero" torna-se, antes, uma maneira de indicar 'construções culturais' - a criação inteiramente social de ideias sobre papéis adequados aos homens e às mulheres. Trata-se de uma forma de se referir às origens exclusivamente sociais das identidades subjetivas de homens e de mulheres. (p. 75)

Assim, as normas sociais definem o que é permitido e esperado que meninos e meninas, rapazes e moças, idosos e idosas façam em suas vidas social e privada, como devem se comportar, se relacionar com o sexo oposto, e ainda, tais regras sociais prescrevem como agências de controle, como escola, família, religião, devem se comportar em relação às mulheres e homens de diferentes idades (Neri, 2014).

Dessa maneira, as relações de gênero, assimiladas como construções sociais de comportamentos de dominação e subordinação, têm resultado, historicamente, em experiências e trajetórias sociais distintas para os sexos. Neri (2014) atenta para o fato de que tais prescrições de gênero criam e propagam 
desigualdades com relação à educação, à carreira, ao trabalho e ao salário recebido por homens e mulheres, com efeitos sobre suas vidas.

De acordo com Araújo (2005), pode-se dizer que o movimento de distribuição de incumbências de gêneros é resultante de condições históricas decorrentes das grandes transformações sociais, econômicas e culturais, especialmente aquelas iniciadas no século XVII. A autora sinaliza que o capitalismo, vertente da agência de controle econômica, enfraqueceu o patriarcado e as mulheres foram se apropriando do lugar público para complementar a renda familiar, uma vez que o homem já não supria sua função de sustentante.

Diante da demanda de trabalhar, "a mulher se defronta com novas questões, como o controle contraceptivo diante da decisão de ter ou não filhos, e a necessidade de dividir tarefas e responsabilidades, na esfera doméstica" (Araújo, 2005, p. 50). No entanto, Da Motta (2015) salienta que apesar de essas práticas culturais terem sido gradualmente desconstruídas, elas ainda norteiam os comportamentos de muitas pessoas.

Entendendo, então, que as diferenças de gênero são fortemente influenciadas pela cultura, existem tarefas consideradas masculinas e outras entendidas como de caráter feminino. Ao homem, a masculinidade pode ser consolidada na dominação da esposa e filhos, no papel de provedor único e na expectativa de ser servido em suas necessidades domésticas (ter comida feita, ter sua roupa lavada, sua casa limpa, ser servido sexualmente, e outros). Da Motta (2015) afirma que cabem aos homens as tarefas feitas fora de casa, como prover sustento ao lar, por exemplo.

Já à mulher, a "prescrição tradicional" descreve atividades domésticas, maior repressão social e sexual, barreiras à permanência em um trabalho socialmente valorizado e em esfera pública (e não domiciliar), disparidades salariais se comparado a homens, dificuldade de acesso à formação e apropriação de seu corpo expresso no controle familiar e reprodutivo (Da Motta, 2015). Nessa direção, Neri (2014) reitera que há uma determinação velada às mulheres para as "tarefas de cuidado com a prole, o lar, os doentes da família e os idosos que precisam de cuidador" (p. 179). Conforme aponta Mafra (2011), o ato de cuidar é comum a todas as culturas, embora suas formas de expressão possam ser as mais variadas.

Nessa direção, Angelo (2009) pontua que "o cuidado está presente nas raízes históricas da mulher" (p. 86) e devido a isto, qualquer compreensão acerca do cuidar deve transitar pela discussão de gênero. Por muito tempo, as funções da mulher estiveram voltadas às atividades domésticas e à criação de filhos, afazeres considerados invisíveis diante de uma sociedade tecnológica e industrializada. Neste contexto, o cuidado vai além de uma atividade de mulher, ele passa a ser uma característica que define sua identidade e seu trabalho (Angelo, 2009), sendo visto como natural, uma vez que está inserido 
socialmente no papel de mãe (Braz \& Ciosak, 2009). Assim, estando a tarefa do cuidar baseada em expectativas sociais, desempenhá-la bem pode significar reconhecimento social, melhora na autoestima e no senso de realização pessoal do cuidador (Mafra, 2011; Perracini \& Neri, 2012).

Em pesquisa realizada por Braz e Ciosak (2009), verificou-se que a decisão por um cuidador principal implica em um processo que envolve todo o sistema familiar, e dentre os motivos que levaram as participantes do estudo a se tornarem cuidadoras, foram identificados o conformismo/resignação, o medo da perda, o compromisso, a compaixão, a imposição familiar e do membro familiar a ser cuidado, além da questão de gênero, que reforça a determinação cultural do papel de cuidador destinado ao sexo feminino. Vale salientar a transmissão de tal determinação cultural sobre as diferentes gerações de mulheres de uma mesma família. Neste sentido, o papel socialmente construído para a mulher a partir de seu enquadramento na família e no ambiente doméstico é baseado na justificativa de que "é assim que deve ser" (Braz \& Ciosak, 2009, p. 377). Assim como salientam os autores citados, o sistema normativo que determina as bases do papel da mulher como cuidadora pode acarretar impactos a sua saúde, bem-estar e qualidade de vida. Por outro lado, Perracini e Neri (2012) ressaltam que a mulher também pode perceber essa atribuição como competência social seja através da eficácia do seu trabalho ou por atenderem as demandas de outros indivíduos.

\section{Impactos na saúde do cuidador(a)}

A prestação de cuidados pode gerar para o familiar que assume e exerce essa função impactos significativos em sua saúde física e mental, e em sua vida social e familiar (Camargo, 2010; Neri, 2014; Seima \& Lenardt, 2011). De acordo com Neri (2014), a ausência de apoios informal ou formal faz com que o cuidador fique mais vulnerável a doenças, à depressão, a estados emocionais negativos e à desorganização de sua vida pessoal, gerando impacto negativo tanto para a família quanto para o idoso. Assim, a família sofre devido às restrições materiais, sociais e por conflitos e o idoso porque fica sujeito a cuidados inadequados e insuficientes (Pinto, Barham, \& Del Prette, 2016).

Uma vez que se encontram envolvidos na prestação de cuidados sem preparação prévia e por falta de suporte social suficiente para a demanda, esses cuidadores se veem obrigados a renunciar emprego, convívio social e até familiar (Seima \& Lenardt, 2011). Essa atividade é, muitas vezes, exercida sem ajuda e reconhecimento de outros membros da família gerando alto grau de sobrecarga e renúncias (Neri, 2014). Essa sobrecarga é associada ao esgotamento emocional (estresse emocional, quadro de depressão) e físico (doenças crônicas), além do isolamento social, conflitos familiares e dificuldades financeiras (Camargo, 2010; Neri, 2014). Corroborando com essa afirmação, de acordo com a metanálise realizada por Pinquart e Sörensen (2003), os cuidadores têm pontuado mais alto 
para depressão e mais baixo em senso de autoeficácia e bem-estar subjetivo do que familiares não cuidadores.

Esses impactos são ainda maiores quando se fala de cuidadores idosos do sexo feminino. Neri (2014) afirma que essas mulheres não estão fisicamente ou emocionalmente preparadas para a função de cuidadoras de idosos dependentes e que a relação de cuidado é envolvida por sentimentos contraditórios, como amor e ódio, cooperação e rivalidade, inveja, vingança e, punição. A autora também ressalta que esses sentimentos contraditórios podem emergir diante do impacto financeiro muitas vezes atrelado a essa função e as necessidades do idoso (abandono do emprego e consequente diminuição da renda mensal, gastos com medicamentos e serviços de saúde, entre outros).

Pinquart e Sörensen (2003) apontam que a maioria dessas cuidadoras são mulheres acima de 65 anos, isto é, são idosas cuidando de idosos (as) e que lidam com demandas competitivas como o cuidar de outros membros familiares além de precisarem cuidar de sua própria saúde. A metanálise também aponta que mulheres que relatam maior ônus, sofrem mais com doenças crônicas, incapacidades e sintomas depressivos, diminuindo sua percepção de satisfação de vida comparado aos homens.

Os dados obtidos por Pinquart e Sörensen (2003) ainda mostram que mulheres exercendo essa função trabalham mais horas, relatam mais problemas comportamentais do idoso (como dificuldades dos idosos para realizar sozinhos as atividades básicas da vida diária) e realizam mais atividades de cuidado oferecendo mais ajuda pessoal do que os cuidadores do sexo masculino. Dessa forma, os declínios da saúde associados ao avanço da idade e ao gênero feminino podem aumentar o ônus dessa população, gerando quadros de sobrecarga e desgaste (Neri, 2014).

Segundo Carvalho et al. (2008), com a crescente inserção da mulher no mercado de trabalho, o que em grande parte implica no trabalho fora de casa, as mulheres passaram a assumir uma dupla jornada de trabalho, sendo responsáveis por seus afazeres formais e informais (cuidados com a casa, os filhos, os pais idosos, os parentes adoentados), contribuindo para a acentuação da sobrecarga. Diante de classes sociais com maior poder aquisitivo, há a contratação de ajudantes (empregadas, babás, assistentes, secretárias, educadoras de creches) para amenizar os impactos desta dupla jornada. Entretanto, estes ajudantes são em sua maioria mulheres - que também exercem uma dupla jornada (Carvalho et al., 2008).

Partindo desses dados considera-se importante refletir acerca do impacto desse papel na vida da mulher cuidadora, considerando as particularidades que as acometem. Há um caráter urgente de busca de conhecimentos especializados para ajudar esses familiares na melhoria da percepção de bem-estar e qualidade de vida (Camargo, 2010). O apoio formal ao cuidador, ou seja, o apoio disponibilizado por instituições e profissionais, traz, portanto, a possibilidade de 
buscar caminhos que ajudem a descobrir novas estratégias de cuidado sem que as mulheres anulem suas próprias necessidades de vida, possibilitando assim que não percebam o cuidar como uma atividade apenas prejudicial ou negativa (Seima \& Lenardt, 2011).

Questionamentos sobre a tarefa de cuidar de idosos

Diante do que foi exposto, é possível observar cinco fatores, que quando analisados em conjunto, permitem algumas considerações sobre o atual papel de cuidador de idosos, bem como possíveis projeções para o futuro. São eles: (a) a cultura como participante na determinação de papéis de gênero, definindo a mulher como a responsável pelo cuidar; (b) a inserção da mulher no mercado de trabalho, (c) a diminuição da taxa de natalidade e consequente redução de familiares para cuidar dos idosos, (d) o crescente número de idosos que precisarão de assistência, (e) o aumento no tempo médio de cuidado exigido por um idoso até seu óbito.

Isto posto, ao manter a ideia de que cuidar de idosos permanecerá como uma função feminina, tem-se a mulher acumulando suas responsabilidades, uma vez que: (1) a mulher deixou de ser apenas "do lar" e passou a ter jornada dupla (continua exercendo as funções domésticas, mas agora é responsável por um trabalho externo ao domicílio); (2) houve uma diminuição da quantidade de filhos por família, reduzindo a quantidade de potenciais cuidadores para o futuro; (3) em contrapartida, está ocorrendo um aumento significativo no número de longevos que precisarão de assistência; (4) além disso, com o aumento da expectativa de vida, a média de anos de cuidados prestados a um idoso dependente tem aumentado consideravelmente.

Vale ressaltar que o aumento exponencial no número de responsabilidades e atividades a serem realizadas, a diminuição da vida social e a falta de tempo para realizar atividades de cuidados pessoais ou prazerosas podem resultar na associação da atividade de cuidado somente a fatores onerosos e que produzem sentimentos negativos (Camargo, 2010), anulando uma possível percepção de satisfação ao exercer essa função. Para se evitar esse quadro, é preciso um esforço de familiares, de estudiosos, do setor público e da sociedade de forma a modificar essa perspectiva negativa do cuidar, adequando as estratégias para realizar esse papel, o qual necessariamente permanecerá presente no cotidiano das famílias brasileiras. É necessário, portanto, que cuidar de um idoso se transforme em algo natural, valorizado e prazeroso, assim como cuidar de um filho. Isso não descarta as dificuldades inerentes ao cuidar, porém é possível acoplar junto a elas, benefícios como: maior vínculo entre cuidador-idoso, sentimentos de capacidade, retribuição, solidariedade, compaixão, maior harmonia intergeracional, momentos prazerosos e agradáveis, entre outros (Cunha, 2011; Oliveira \& Caldana, 2012). 
Carvalho et al. (2008) ressaltam que há uma desvalorização do papel de cuidador e questionam se esse fenômeno ocorre porque é um papel historicamente atribuído à mulher, ou a mulher é desvalorizada porque historicamente tendeu a assumir esse papel excluído do trabalho remunerado. As atividades tidas como "naturalmente femininas" apresentam baixo ou nenhum retorno monetário quando são exercidas na própria família. Ao se enquadrar o cuidar de idosos nessa categoria, considera-se que essa atividade deverá ser exercida por mulheres e que a mesma não deve receber por esse trabalho.

Intensificando esse contexto, tem-se o grau de dependência do idoso como um fator facilitador do aumento de atividades designadas ao cuidador, o qual sem um apoio formal pode ter de abandonar sua carreira profissional (Seima \& Lenardt, 2011) tendo que se dedicar integralmente aos cuidados de seu parente idoso. Diante desse cenário, a cuidadora tem sua renda mensal diminuída, por tempo indeterminado, tendo que muitas vezes se utilizar da receita do idoso para arcar com as despesas da casa e dos seus gastos pessoais.

No entanto, quando o familiar idoso vier a óbito, a mulher que outrora era cuidadora deixa tal função, podendo encontrar-se desamparada diante da necessidade urgente de se reinserir no mercado de trabalho. Assim, há um problema cultural ao se marginalizar essa atividade e defini-la como algo feminino. Também, há um problema econômico ao ignorar a necessidade dessas mulheres serem recompensadas monetariamente. Para tanto, algumas alterações em como avaliar o cuidar precisariam ser feitas visando maior valorização dessa ocupação.

Existe um fato concreto que é o aumento expressivo de idosos dependentes para os próximos anos (Alisson, 2016). Ao que se percebe, a curto e médio prazo, não há perspectiva de eliminar a assistência familiar ao idoso dependente. No entanto, Neri (2014) aponta que com a redução do número de membros por família somada às mudanças que vêm acontecendo nos papéis da mulher deve acontecer uma diminuição na disponibilidade de cuidadores familiares. Camarano e Kanso (2010) fazem uma projeção baseada em dados do IBGE dos anos 1998, 2003 e 2008 indicando essa provável redução da oferta de cuidador familiar. As autoras apontam que em 2020 deve haver quatro vezes mais pessoas não sendo assistidas por membros da família. Dessa forma cresce a necessidade de que o Estado, a família e o mercado privado tenham que dividir as responsabilidades por esse idoso dependente que demanda um cuidado por períodos cada vez mais longos (Camarano \& Kanso, 2010). Diante desse possível cenário, parece sensato e necessário a elaboração e o aumento de projetos e serviços que visem atender essa demanda crescente, não apenas capacitando cuidadores familiares a exercerem essa função de forma adequada, mas também no sentido de aumentar a oferta de programas e serviços acessíveis a esses idosos. 
Outra reflexão a ser acrescentada se refere à demanda por práticas de coparentalidade, que pode ser definida como a participação equilibrada dos pais diante das necessidades dos filhos (Frizzo, Kreutz, Schmidt, Piccinini \& Bosa, 2005). Segundo Carvalho et al. (2008), os homens ainda figuram como coadjuvantes na tarefa de cuidar e apesar de ocorrerem mudanças culturais, como uma participação mais presencial do homem no lar, ainda persiste uma rigidez quanto às funções de cada gênero dentro das esferas de atividades domésticas e do cuidado com os filhos. Nessa direção, é necessário que se estabeleça socialmente novas normas de se comportar e se relacionar, pois de acordo com Araújo (2005), a aceitação de diferentes padrões comportamentais "tem permitido aos homens se libertarem do peso do machismo e às mulheres se libertarem do imperativo do feminino, (...) e não seguirem imperativos categóricos determinados pelo gênero (...). Nessa perspectiva, a reconstrução do feminino leva necessariamente à reconstrução do masculino" (p. 48).

Assim, em uma relação dinâmica entre os gêneros, busca-se maior espaço e aceitação social para que o homem exerça também o cuidado com os filhos e que tal prática se estenda aos cuidados com o idoso, modificando o cenário atual em que mulheres cuidadoras atuam quase que solitariamente nesse papel de responsáveis por senescentes.

As transformações almejadas acima embora complexas são possíveis e necessárias se se busca transformar beneficamente 0 conceito e as consequências do cuidar de idoso, porém, precisa-se, também, pensar em soluções a curto prazo para resolver as demandas atuais. Em relação à demanda psicológica é possível elucidar algumas estratégias que estão sendo realizadas, como: (a) intervenções voltadas para o cuidador (exemplo: o Programa dos 3Es (Ferreira \& Barham, 2016) e a Associação Brasileira de Alzheimer - ABRAz), (b) alternativas para minimizar o carga horária do cuidador, (exemplo: centro-dias), (c) estrutura de saúde para auxiliar o cuidador e o idoso (exemplo: o Programa Saúde Família ou o Programa Melhor em Casa) e (d) divulgação sobre as vantagens do cuidar familiar e os benefícios desse serviço ser realizado por vários membros da família (como propaganda e marketing). Porém, tais alternativas, ainda que muitas sejam de qualidade, são escassas para a população, visto a quantidade de cuidadores que precisam de amparo (Neri, 2014). Por isso, há uma necessidade emergencial de aumentar esses serviços, bem como de criar outros de qualidade, e com isso, disponibilizar essas alternativas para que os cuidadores exerçam seu papel a partir de condições que possibilitem um cuidado de qualidade, que tenham percepções positivas quanto ao cuidar e, concomitantemente, que não prejudique sua qualidade de vida e seu ambiente social.

Em relação à demanda econômica é preciso pensar em como inserir esses cuidadores no mercado após se desvincularem do papel de cuidador. Também, é preciso refletir em estratégias que os assegurem a receber remuneração como 
cuidador, de forma a ter uma independência financeira e, ainda, seu serviço valorizado. Em longo prazo, é preciso a elaboração de projetos de políticas públicas que considerem as necessidades desses cuidadores e que percebam essa tarefa como algo importante e crucial para o avanço da sociedade, de forma que assistir um idoso seja realizado por membros capacitados e que muitos familiares almejem realizar essa função, uma vez que cuidar de um idoso não será mais um papel menosprezado e não valorizado socialmente. Com isso, poder-se-ia assegurar que em uma população na qual a existência de idosos dependentes é uma realidade crescente, será crescente também o número de cuidadores capacitados, saudáveis e orgulhosos de exercerem sua função.

\section{CONSIDERAÇÕES FINAIS}

A partir da discussão geral enfatizada no presente trabalho, conclui-se que discutir acerca da influência da cultura na determinação dos papéis de gênero, mais especificamente na atividade feminina de cuidar de um idoso, é um compromisso desafiador e amplo, pois engloba a multidisciplinaridade de conhecimento e envolve uma interação complexa entre atributos de gênero e vivências culturais. Todavia, apesar de intrincado, tal empenho é necessário e valorizado quando se pensa no contexto do envelhecer no qual muitos já vivenciam e muitos mais vivenciarão.

Dessa maneira, as implicações da reflexão acerca da estruturação social que estabelece a mulher como cuidadora podem constituir evidências para uma maior ênfase no desenvolvimento imediato de políticas sociais e de saúde direcionadas à mulher. Concomitantemente, tal reflexão contribui para uma mudança relacionada às definições de papéis, de forma a se estabelecer o papel de cuidar para o familiar que estiver mais apto a realizá-lo, não sendo o gênero o principal determinante para definir essa função. Por fim, almeja-se que este artigo auxilie na transformação da visão atual do cuidar de idosos, em que a assistência é tida, na maioria das vezes, como uma tarefa estressante e sem fatores positivos, tornando-a uma atividade valorizada e composta por diversos componentes favoráveis ao cuidador.

Para além deste breve estudo, seria necessário avançar na reflexão sobre a atividade de cuidar e a função social da mulher, buscando esclarecimentos acerca de questões como: (a) Qual o valor social do cuidado? (b) Há relação entre a desvalorização da atividade de cuidar e a subordinação histórica da mulher? (c) Qual a parcela psicobiológica na determinação de papéis de gênero? (d) As transformações sociais trazem em si alterações no valor social à mulher? (e) Quem serão os cuidadores da próxima década? (f) Como otimizar a rede de suporte social do cuidador de modo a angariar maior participação de outros familiares no processo de cuidar? (g) Seria o planejamento de vida uma estratégia para auxiliar o cuidador a melhor se adaptar a essa função? (h) Como 
disponibilizar programas de qualidades para pessoas e familiares que irão se tornar cuidadores de idosos? (i) Como reconfigurar a divisão de tarefas de maneira a tornar o homem um protagonista, ao lado da mulher, na atividade de cuidar? (j) Seria o avanço e intensificação do feminismo um fator de mudança na condição atual da mulher cuidadora?

Dessa forma, considerando ser crescente o número de cuidadores (formais e informais) de idosos no Brasil e diante dos questionamentos aqui levantados, espera-se que novas reflexões e estudos venham contribuir para a compreensão de como se dá a escolha pelo cuidador e os impactos dessa atividade em sua vida. Espera-se ainda que haja maior envolvimento de pessoas com o tema, de modo a favorecer a elaboração de alternativas e intervenções, objetivando tornar essa função minimamente planejada, mais prazerosa e menos árdua ao cuidador.

\section{DECLARAÇÃO DE CONFLITOS DE INTERESSE}

Os autores declaram não haver conflitos de interesse.

\section{REFERÊNCIAS}

Alisson, E. (2016, July 06). Brasil terá a sexta maior população de idosos do mundo em 2025. Agência FAPESP. Recuperado de http://agencia.fapesp.br/brasil_tera_sexta_maior_populacao_de_idosos_no _mundo_ate_2025/23513/

Angelo, M. (2009). Cultura e cuidado da família. In E. Nakamura, D. Martin, \& J. F. Q. Santos (Eds.), Antropologia para enfermagem. São Paulo, SP: Manole. Araújo, M. D. F. (2005). Diferença e igualdade nas relações de gênero: Revisitando o debate. Psicologia Clínica, 17(2), 41-52. http://dx.doi.org/10.1590/S0103-56652005000200004

Barham, E. J., Pinto, F. N. F. R., Andrade. A. R., Lorenzini, M. F. J., \& Ferreira, C. R. (2015). Fundamentos e estratégias de intervenção para a promoção de saúde mental em cuidadores de idosos. In S. G. Murta, C. Leandro-França, K. B. Santos, \& L. Polejack (Eds.), Prevenção e promoção em saúde mental: Fundamentos, planejamento e estratégias de intervenção (pp. 844 - 862). Novo Hamburgo, RS: Sinopsys Editora.

Bauab, J. P., \& Emmel, M. L. G. (2014). Mudanças no cotidiano de cuidadores de idosos em processo demencial. Revista Brasileira de Geriatria e Gerontologia, 17(2), 339-352. http://dx.doi.org/10.1590/S180998232014000200011

Baum, W. M. (2006). Compreender o behaviorismo: Comportamento, cultura e evolução (M. T. A. Silva et al., Trans.). Porto Alegre, RS: Artmed (Trabalho original publicado em 1994). 
Berg, J. A. \& Woods, N. F. (2009). Global women's health: A spotlight on caregiving. Nursing Clinics of North America, 44, 375-384. doi: $10.1016 /$ j.cnur.2009.06.003

Brasil, M. C., \& Andrade, C. C. (2013). Reconfiguração de campo do familiar cuidador do portador de Alzheimer. Psicologia em Estudo, Maringá, 18(4), 713-723. doi:10.1590/S1413-73722013000400013

Braz, E., \& Ciosak, S. I. (2009). O tornar-se cuidadora na senescência. Escola Anna Nery Revista de Enfermagem, 13(2), 372-377. doi:10.1590/S141481452009000200019

Burlá, C., Py, L. \& Scharfstein, E. A. (2010). Como estão sendo cuidados os idosos no final da vida? In A. A. Camarano (Ed.), Cuidados de longa duração para a população idosa: Um novo risco social a ser assumido (pp. 271-302). Rio de Janeiro, RJ: IPEA.

Cabral, F., \& Díaz, M. (1998). Relações de gênero. In Secretaria Municipal de Educação de Belo Horizonte/Fundação Odebrecht (Eds.), Cadernos afetividade e sexualidade na educação: Um novo olhar, (pp. 142-150). Belo Horizonte, MG: Editora Rona.

Camarano, A.A \& Kanso, S. (2010). Como as famílias brasileiras estão lidando com idosos que demandam cuidados e quais as perspectivas futuras? $A$ visão mostrada pelas PNADS. In A. A. Camarano (Ed.), Cuidados de longa duração para a população idosa: Um novo risco social a ser assumido? (pp. 93-122). Rio de Janeiro, RJ: IPEA.

Camargo, R. C. V. F. (2010). Implicações na saúde mental de cuidadores de idosos: uma necessidade urgente de apoio formal. Revista Eletrônica de Saúde Mental Álcool e Drogas, 6(2), 231-254. Recuperado em 14 mai 2018, de http://pepsic.bvsalud.org/scielo.php?script=sci_arttext\&pid=S180669762010000200002.

Carvalho, A. M. A, Cavalcanti, V. R. S., Almeida, M. A. \& Bastos, A. C. S (2008). Mulheres e cuidado: Bases psicobiológicas ou arbitrariedade cultural? Paidéia, 18(41), 431-444. doi:10.1590/S0103-863X2008000300002

Cunha, M. C. M. C. (2011). Impacto positivo do acto de cuidar no cuidador informal do doso: Um estudo exploratório nos domicílios do concelho de Gouveia. (Dissertação de Mestrado). Universidade de Lisboa, Lisboa, Portugal.

Da Motta, A. B. (2015). As dimensões de gênero e classe social na análise do envelhecimento. Cadernos Pagu, (13), 191-221. Recuperado em 14 mai 2018, de http://www.bibliotecadigital.unicamp.br/document/?down=51317.

Debert, G. G. \& Oliveira, A. M. (2015). A profissionalização da atividade de cuidar de idosos no Brasil. Revista Brasileira de Ciência Política, (18), 7-41. doi:10.1590/0103-335220151801 
Ferreira, C. R., \& Barham, E. J. (2016). Uma intervenção para reduzir a sobrecarga em cuidadores que assistem idosos com doença de Alzheimer. Revista Kairós Gerontologia, 19(4), pp. 111-130. Recuperado em 14 mai 2018, de https://revistas.pucsp.br/index.php/kairos/article/view/31645/22037.

Frizzo, G. B., Kreutz, C. M., Schmidt, C. P., Piccinini, C. A., \& Bosa, C. (2005). O conceito de coparentalidade e suas implicações para a pesquisa e para a clínica. Revista Brasileira de Crescimento e Desenvolvimento Humano, 15(3), 84-93. Recuperado em 14 mai 2018, de http://www.revistas.usp.br/jhgd/article/view/19774/21841.

Leite, C. D. S. M., Menezes, T. L. M., Lyra, E. V. V., \& Araújo, C. M. T. (2014). Conhecimento e intervenção do cuidador na doença de Alzheimer: Uma revisão da literatura. Jornal Brasileiro de Psiquiatria, 63(1), 48-56. doi:10.1590/0047-2085000000007.

Karsch, U. M. (2003). Idosos dependentes: Famílias e cuidadores. Caderno de Saúde Pública, 19(3), 861-866. http://dx.doi.org/10.1590/S0102$311 \times 2003000300019$.

Mafra, S. C. T. (2011). A tarefa do cuidar e as expectativas sociais diante de um envelhecimento demográfico: A importância de ressignificar o papel da família. Revista Brasileira de Geriatria e Gerontologia, 14(2), 353-364. doi:10.1590/S1809-98232011000200015.

Malott, M. E. (1999). Creating lasting organizational changes. Performance improvement, 38(2), 33-36. doi:10.1002/pfi.4140380209

Martone, R. C., \& Todorov, J. C. (2007). O desenvolvimento do conceito de metacontingência. Revista Brasileira de Análise do Comportamento, 3(2), 181-190. doi:10.18542/rebac.v3i2.830

Ministério do Trabalho (2016). Classificação Brasileira de Ocupações: CBO. Brasília, DF: MTE, SPPE. Recuperado de: http://www.mtecbo.gov.br/cbosite/pages/saibaMais.jsf

Moreira, M. B. (2013). Comportamento e práticas culturais. Brasília, DF: Instituto Walden4.

Neri, A. L. (2014). Palavras-chave em gerontologia. Campinas, SP: Editora Alínea.

Oliveira, A. P. P., Caldana, R. H. L. (2012). As repercussões do cuidado na vida do cuidador familiar do idoso com demência de Alzheimer. Saúde e Sociedade, 21(3), 675-685. doi:10.1590/S0104-12902012000300013.

Perracini, M. R., \& Neri, A. L. (2012) Tarefas de cuidar: Com a palavra, mulheres cuidadoras de idosos de alta dependência. In A. L Neri (Ed.), Cuidar de idosos no contexto da família: Questões psicológicas e sociais (3a. ed., pp. 165-201). Campinas, SP: Alínea. 
Pinquart, M. \& Sörensen, S. (2003). Differences between caregivers and noncaregivers in psychological health and physical health: A meta-analysis. Psychology and Aging, 18(2), 250-267. doi:10.1037/0882-7974.18.2.250

Pinto, F. N. F. R, Barham, E. J., \& Albuquerque, P. P. (2013). Idosos vítimas de violência: Fatores sociodemográficos e subsídios para futuras intervenções. Estudos e Pesquisas em Psicologia, 13(3), 1159-1181. Recuperado em 14 mai 2018, de http://pepsic.bvsalud.org/pdf/epp/v13n3/v13n3a18.pdf .

Pinto, F. N. F. R., Barham, E. J., \& Del Prette, Z. A. P. (2016). Interpersonal conflicts among family caregivers of the elderly: The importance of social skills. Paidéia, 26(64), 161-170. doi:10.1590/1982-43272664201605

Presidência da República, Casa Civil, Subchefia para Assuntos Jurídicos (2003). Lei no 10.741, de $1^{\circ}$ de outubro de 2003. Dispõe sobre o Estatuto do Idoso e dá outras providências. Brasília, DF: Diário Oficial da União. Recuperado de: http://www.planalto.gov.br/ccivil_03/leis/2003/L10.741.htm

Seima, M. D., \& Lenardt, M. H. (2011). A sobrecarga do cuidador familiar de idoso com Alzheimer. Textos \& Contextos, 10(2), 388-398. Recuperado em 14 mai 2018, http://revistaseletronicas.pucrs.br/ojs/index.php/fass/article/download/990 $1 / 7341$.

Scott, J. (1995). Gênero: Uma categoria útil de análise histórica. Educação \& Realidade, 20(2), 71-99. Recuperado em 14 mai 2018, de http://seer.ufrgs.br/index.php/educacaoerealidade/article/view/71721/4066 7.

Silva, R. M. F. M., \& Santana, R. F. (2014). Diagnóstico de enfermagem "tensão do papel de cuidador": Revisão integrativa. Revista Brasileira de Geriatria e Gerontologia, 17(4), 887-896. doi:10.1590/1809-9823.2014.13069

Sinnott, J. D., \& Shifren, K. (2001). Gender and aging: Gender differences and gender roles. In Birren, J. E.; Schaie, KW. (Eds.), Handbook of Psychology and Aging (5a ed., pp. 454-467). San Diego, CA: Academic Press.

Schneider, R. H. \& Irigaray, T. Q. (2008). O envelhecimento na atualidade: Aspectos cronológicos, biológicos, psicológicos e sociais. Estudos de Psicologia (Campinas), 25(4), 585-593. Recuperado em 14 mai 2018, de http://www.scielo.br/pdf/estpsi/v25n4/a13v25n4.pdf.

Skinner, B. F. (1981). Selection by consequences. Science, 213, 501-504. doi:10.1126/science.7244649

Skinner, B. F. (1983). O mito da liberdade (E. R. B. Rebelo, Trans.). São Paulo, SP: Summus. (Texto original publicado em 1971).

Skinner, B. F. (2003). Ciência e comportamento humano (J. C. Todorov \& R. Azzi, Trans.) 11a ed. São Paulo, SP: Martins Editora (Trabalho original publicado em 1953). 


\section{Sobre as autoras}

Camila Rafael Ferreira é psicóloga e mestranda pela Universidade Federal de São Carlos. Realiza pesquisas sobre desenvolvimento do adulto e do idoso, estratégias de coping, treinamento de profissionais e intervenções pesicoeducativas para cuidadores que assistem idosos. Recebe financiamento de pesquisa da FAPESP. camila_rferreira@hotmail.com

Letícia Isaac é psicóloga pela Universidade Federal de São Carlos e mestranda na Universidade Federal de São Carlos. Trabalha na linha Comportamento Social e Processos Cognitivos, realizando pesquisas sobre o desenvolvimento adulto e do idoso. leticia.isaac@hotmail.com Vanessa Santiago Ximenes é psicóloga pela Universidade Estadual de Londrina, especialista em Psicoterapia por Contingências de Reforçamento pelo Instituto de Terapia por Contingências de Reforçamento e mestranda na Universidade Federal de São Carlos. Trabalha na linha Comportamento Social e Processos Cognitivos, realizando pesquisas sobre o desenvolvimento adulto e do idoso. Recebe financiamento de pesquisa da CAPES. vanessasximenes@hotmail.com

Certificamos que todas as autoras participaram suficientemente do trabalho para tornar pública sua responsabilidade pelo conteúdo. Isto é, todas tiveram igual contribuição em todas as etapas de produção do artigo.

As autoras agradecem a Coordenação de Aperfeiçoamento de Pessoal de Nível Superior (CAPES) e a Fundação de Amparo à Pesquisa do Estado de São Paulo (Fapesp) pelo financiamento da pesquisa. Agradecem, ademais, os Prof. Dr. Júlio César de Rose, Profa. Dra. Maria Stella Coutinho de Alcântara Gil e Profa. Dra. Elizabeth Joan Barham pela leitura da versão inicial do texto e pelas discussões teóricas ao longo da elaboração do trabalho.

Recebido em: 07/03/2017

Revisado em: 08/04/2017

Aceito em: 09/06/2017 